\title{
Adaptive laboratory evolution triggers pathogen-dependent broad-spectrum antimicrobial potency in Streptomyces
}

\author{
Dharmesh Harwani, Jyotsna Begani, Sweta Barupal and Jyoti Lakhani* (i)
}

\begin{abstract}
Background: In the present study, adaptive laboratory evolution was used to stimulate antibiotic production in a Streptomyces strain JB140 (wild-type) exhibiting very little antimicrobial activity against bacterial pathogens. The seven different competition experiments utilized three serial passages (3 cycles of adaptation-selection of 15 days each) in which Streptomyces strain (wild-type) was challenged repeatedly to one (bi-culture) or two (tri-culture) or three (quadri-culture) target pathogens. The study demonstrates a simple laboratory model to study the adaptive potential of evolved phenotypes and genotypes in Streptomyces to induce antibiotic production.
\end{abstract}

Results: Competition experiments resulted in the evolution of the wild-type Streptomyces strain JB140 into the seven unique mutant phenotypes that acquired the ability to constitutively exhibit increased antimicrobial activity against three bacterial pathogens Salmonella Typhi (NCIM 2051), Staphylococcus aureus (NCIM 2079), and Proteus vulgaris (NCIM 2027). The mutant phenotypes not only effectively inhibited the growth of the tested pathogens but were also observed to exhibit improved antimicrobial responses against one clinical multidrug-resistant (MDR) uropathogenic Escherichia coli (UPEC 1021) isolate. In contrast to the adaptively evolved mutants, only a weak antimicrobial activity was detected in the wild-type parental strain. To get molecular evidence of evolution, RAPD profiles of the wild-type Streptomyces and its evolved mutants were compared which revealed significant polymorphism among them.

Conclusion: The competition-based adaptive laboratory evolution method can constitute a platform for evolutionary engineering to select improved phenotypes (mutants) with increased antibacterial profiles against targeted pathogens.

Keywords: Streptomyces, Adaptive evolution, Induction, Antimicrobials, Mutants, RAPD

\section{Background}

The discovery of antibiotics by Alexander Flemming in 1929 revolutionized the treatment of diseases caused by microbial pathogens [1]. At present times, the numbers of infections caused by MDR Staphylococcus aureus, Acinetobacter baumannii, Klebsiella pneumoniae, Pseudomonas aeruginosa, Mycobacterium tuberculosis, etc., have been found to pose serious threats to human health. Consequently, efforts are being made

*Correspondence: jyotilakhani@mgsubikaner.ac.in

Department of Computer Science, Maharaja Ganga Singh University, Bikaner, Rajasthan, India globally to develop new antibiotic compounds to prevent these deadly pathogens [2]. The majority of antibiotics are natural products or their semi-synthetic derivatives that originated from the genus Streptomyces in the order Actinomycetales [3, 4], which are known to be distributed mainly in soil and marine sediments. The clinically important antibiotics produced by Streptomyces species include tetracyclines, aminoglycosides (e.g., streptomycin, neomycin, kanamycin), macrolides (e.g., erythromycin), chloramphenicol, and rifamycins $[5,6]$. Many new antibiotics were isolated from actinomycetes between the late 1940s and the late 1960s, a period of the "Golden Age" of antibiotic discovery. After that, the rate 
of discovery gradually declined due to the frequent rediscovery of already known chemical compounds (secondary metabolites). However, the rapid increase in the recent genome sequence information suggests that this source is still not yet exhausted [7-12].

In the present paper, we hypothesized that a strain of Streptomyces that exhibits very littleantimicrobial activity could undergo evolution, if challenged against a bacterial pathogen. Repeated exposure to a pathogen could lead to the production of antimicrobials that are usually not produced by its parental strain. It was also hypothesized that challenging the wild-type strain with more than one pathogen in adaptive evolution may elicit a different response. In other studies, co-cultures of two different organisms have been observed to improve the production of antimicrobial molecules [13-17]. Importantly, these experiments have not used adaptive-selection cycles as these used in the present study. The co-culture experiments involve the cultivation of two (or more) microbes (interspecies interactions) in the same closed and restricted environment for a certain period. The supernatant from these mixed cultures and mono-culture (control) is then analyzed for their bio-activity or no bioactivity. In contrast to this approach, in the laboratory evolution experiments described in the present study, the wild-type Streptomyces strain JB140 is co-cultured with different bacterial pathogens in the bi-, tri-, and quadriculture assays. After isolation and purification of the Streptomyces phenotypes from the first cycle, these phenotypes were repeatedly exposed (three successive cycles of adaptation-selection of 15 days each) to the bacterial pathogens until the bio-activity was detected.

\section{Methods}

\section{Bacterial strains}

The present research utilized a Streptomyces strain JB140 (wild-type) exhibiting very little antimicrobial activity, its seven mutants, namely JB140 ${ }^{P \nu}$, JB140 $0^{S t}, \mathrm{JB} 140^{S a}$, $\mathrm{JB} 140^{S a, S t}$, JB140 $0^{S a, P v}, \mathrm{JB} 140^{S t, P v}$, and JB140 ${ }^{S a, S t, P_{v}}$ purified after the third (III) cycle of serial adaptation and selection as mentioned below in the results section, three bacterial pathogens Salmonella Typhi (NCIM 2051), Staphylococcus aureus (NCIM 2079), Proteus vulgaris (NCIM 2027), and one clinical multidrug-resistant (MDR) uropathogenic Escherichia coli (UPEC 1021) isolate.

\section{Selective isolation, maintenance, and characterization}

The isolate JB140 was recovered from the soil sample collected at Ganganagar $\left(29.9038^{\circ} \mathrm{N}, 73.8772^{\circ} \mathrm{E}\right)$ region falling in the arid Thar desert in the Indian state of Rajasthan. After selective isolation, using the modified actinomycete selective (MAS) agar medium, the pure culture of the isolate was stored at $-40{ }^{\circ} \mathrm{C}$ using $20 \%(\mathrm{w} / \mathrm{v})$ sterile glycerol until further use. The isolate JB140 was further subjected to its morphological studies using the bright field and scanning electron microscopy (SEM). The sample for SEM analysis was prepared according to the protocol described by Srinivasan et al. [18]. Phenotypic characterization of the isolate was performed by growing it on ISP (International Streptomyces Project) media as described by Shirling and Gottlieb [19]. Taxonomic identification of the isolate JB140 was performed using 16SrRNA gene sequence analysis which is described below in the methods section.

\section{Cultivation and evaluation of antimicrobial activity of the isolate JB140}

After phenotypic characterization, the isolate was screened for its antibacterial activity against bacterial pathogens in primary and secondary screening using agar plug $[20,21]$ and agar well diffusion $[22,23]$ methods, respectively. For small-scale cultivation, the isolate was cultured in a 1L flask containing $200 \mathrm{~mL}$ of ISP2 medium. The cultivation was carried out at $37{ }^{\circ} \mathrm{C}$ for 10 days at an agitation rate of $120 \mathrm{rpm}$. The growth was monitored by measuring optical density at $600 \mathrm{~nm}$ for 15 days at 2 days intervals. After cultivation, the broth was extracted with ethyl acetate. The extract was concentrated to dryness and the residue crude extract was dissolved in methanol and stored at $4{ }^{\circ} \mathrm{C}$ for further use. The methanolic extracts were used to evaluate antimicrobial activity in the agar well diffusion method. Antimicrobial activity at different time points was also monitored during the time course of cultivation. The antimicrobial activity was assayed against three type strains Salmonella Typhi (NCIM 2051), Staphylococcus aureus (NCIM 2079), Proteus vulgaris (NCIM 2027), and one clinical MDR uropathogenic Escherichia coli isolate.

\section{Adaptive evolution protocol}

In the present adaptive laboratory evolution protocol, seven different competition experiments were performed in which a wild-type (WT) Streptomyces strain JB140 that exhibits very little antimicrobial activity was challenged against bacterial pathogens in different ways as depicted in Fig. 1. The first three (1st, 2nd, 3rd) experiments involved JB140 ${ }^{\mathrm{WT}}$ and one of the three target pathogens (a bi-culture competition consisting of JB140 ${ }^{\mathrm{WT}}$ and $P$. vulgaris or $S$. Typhi or $S$. aureus). The next three experiments (4th, 5th, 6th) involved JB140 ${ }^{\mathrm{WT}}$ and two target pathogens (a tri-culture competition consisting of $\mathrm{JB} 140^{\mathrm{WT}}$ and $S$. aureus + S. Typhi or S. aureus + P. vulgaris or $S$. Typhi + P. vulgaris). The last experiment (7th) involved JB140 ${ }^{\mathrm{WT}}$ and three target pathogens (a quadriculture competition consisting of JB140 ${ }^{\mathrm{WT}}$ and $S$. aureus $+S$. Typhi + P. vulgaris). A mono-culture involving only 


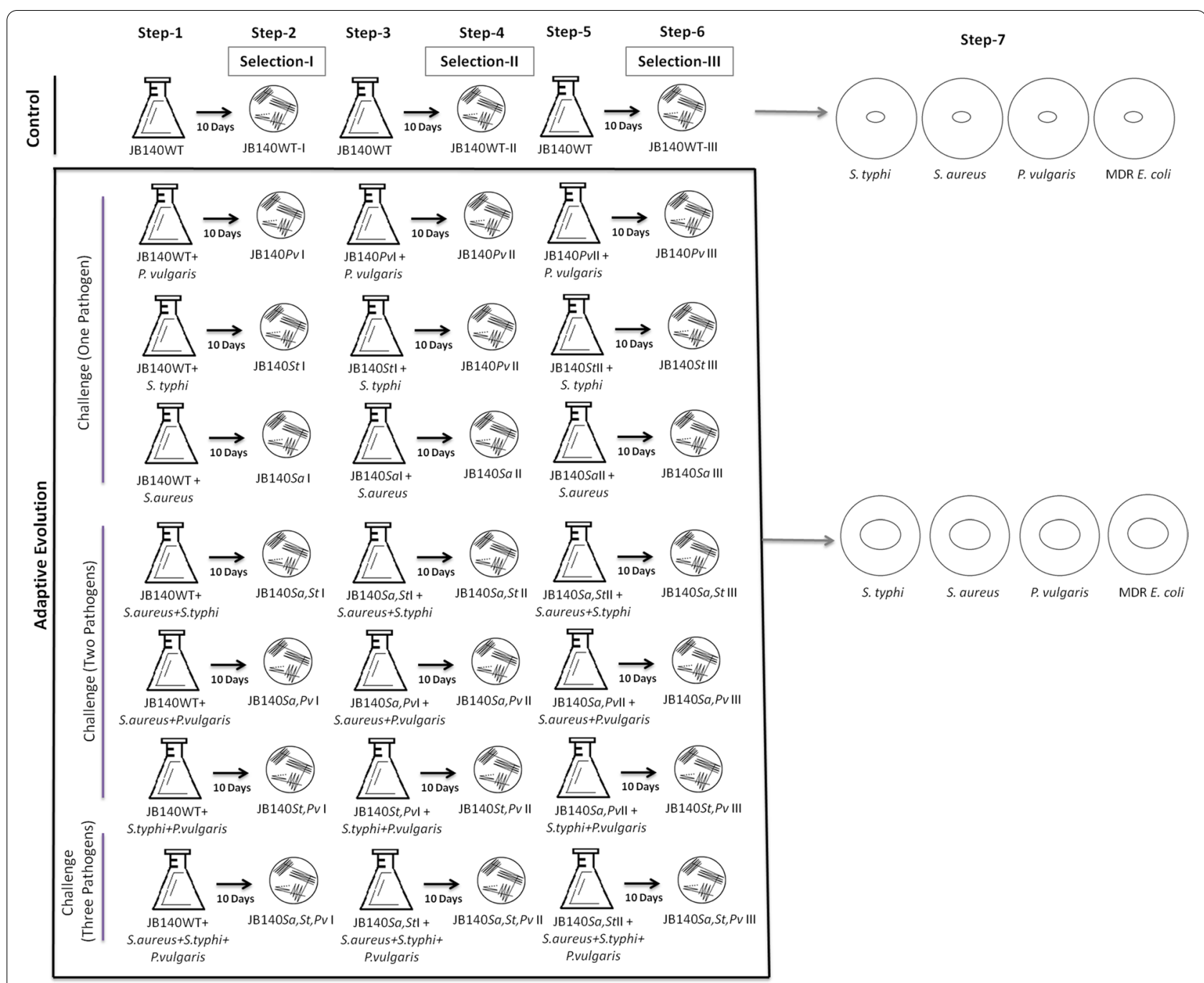

Fig. 1 Adaptive evolution protocol (seven-steps) wherein a weak antibiotic-producing Streptomyces strain JB140 was challenged against bacterial pathogens

$\mathrm{JB} 140^{\mathrm{WT}}$ served as an internal control. The seven experiments were performed separately by inoculating $50 \mathrm{~mL}$ of ISP2 broth medium in a 250-mL flask with a loopful of JB140 ${ }^{\text {WT }}$ mycelia. After inoculation, the flasks were covered with a cotton plug and incubated at $37{ }^{\circ} \mathrm{C}$ in a shaker incubator at $100 \mathrm{rpm}$ for $48 \mathrm{~h}$. After observing the visible growth of $\mathrm{JB} 140^{\mathrm{WT}}$, the flasks for bi-culture, tri-culture, and quadri-culture were inoculated accordingly with $100 \mu \mathrm{l}$ (optical density at $600 \mathrm{~nm}=0.50$ ) of the target pathogen(s) and incubated at $37^{\circ} \mathrm{C}$ for 10 days as shown in Fig. 1 (step 1). The flask for mono-culture contained only JB140 ${ }^{\mathrm{WT}}$.

After this step, on the eleventh day, $100 \mu \mathrm{l}$ from 10-day old mono-culture, bi-culture, tri-culture, and quadri-culture were spread on the fresh ISP2 agar medium and incubated at $37{ }^{\circ} \mathrm{C}$ for 5 days to separate
JB140 WT-I (control), JB140 ${ }^{P v-\mathrm{I}}$ (bi-culture), JB140 ${ }^{S t-\mathrm{I}}$ (bi-

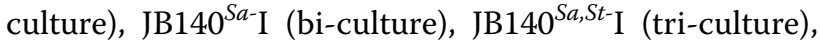
$\mathrm{JB} 140^{S a, P v_{-}}$I (tri-culture), JB140 ${ }^{S t, P v_{-} \text {I }}$ (tri-culture), and $\mathrm{JB} 140^{S a, S t, P \nu_{-} \mathrm{I}}$ (quadri-culture) from their respective flasks (step 2) (Fig. 1). After purification, the next cycle of adaptation-selection was repeated by inoculating purified wild-type and evolved mutants from step 2 into the fresh ISP2 medium. It is important to mention here that the flasks in the successive steps were introduced with freshly grown pathogen/s from their respective stocks. The inoculated flasks were incubated for another 10 days (step 3; II cycle). After incubation, the mixed cultures were purified to obtain JB140 ${ }^{\mathrm{WT}}$-II (control), JB140 ${ }^{P v-I I}$ (bi-culture), JB140 ${ }^{S t-I I}$ (bi-culture), JB140 ${ }^{S a-}$ II (bi-culture), JB140 ${ }^{S a, S t}$ II (tri-culture), JB140 ${ }^{S a, P v-}$ II (triculture), JB140 ${ }^{S t, P v_{-}} \mathrm{II}$ (tri-culture), and $\mathrm{JB} 140^{S a, S t, P v_{-}} \mathrm{II}$ 
(quadri-culture) from their respective flasks (step 4). The adaptive evolution cycle (III cycle) was again repeated to start a new adaptation-selection cycle in steps 5 and 6 to finally receive the wild-type JB140 ${ }^{\mathrm{WT}}$-III and evolved

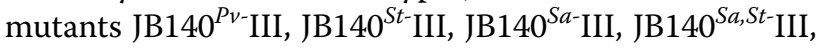
JB140 ${ }^{S a, P v-}$ III, JB140 $0^{S t, P v-}$ III, and JB140 ${ }^{S a, S t, P v-I I I . ~}$

The protocol described here, consisting of six main steps that took $\sim 45$ days to complete (Fig. 1). The wildtype and evolved isolates were preserved in the glycerol stocks $(20 \% \mathrm{v} / \mathrm{v})$ at $-40{ }^{\circ} \mathrm{C}$. After each cycle of adaptionselection, the antimicrobial activities of the wild-type and evolved mutants were assayed against pathogenic Salmonella Typhi (NCIM 2051), Staphylococcus aureus (NCIM 2079), and Proteus vulgaris (NCIM 2027) using the agar well diffusion method. The antimicrobial activity of the mutants purified after the third cycle was also tested against a clinical MDR uropathogenic Escherichia coli (UPEC 1021) isolate in step 7. The detailed prototype of the present method has been also provided in supplementary data (Fig. S1 and Fig. S2).

\section{DNA extraction, sequencing, and phylogenetic analysis}

The wild-type isolate JB140 and its evolved mutants JB140 ${ }^{P v-}$ III, JB140 $0^{S t}$ III, JB140 ${ }^{S a-}$ III, JB140 ${ }^{S a, S t}$ III,

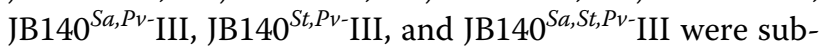
jected to 16SrRNA gene sequence analysis [24] for their precise identification. The genomic DNA of each isolate was extracted using a method of $\mathrm{Li}$ et al. [25]. 16SrRNA gene from each was amplified using a primer pair 27F 5'AGA GTT TGA TCC TGG CTC AG3' and 1492R 5'GGT TAC CTT GTT ACG ACT T3'. The reaction started with an initial denaturation at $95{ }^{\circ} \mathrm{C}$ for $5 \mathrm{~min}$, followed by 30 cycles of DNA denaturation at $95{ }^{\circ} \mathrm{C}$ for $1 \mathrm{~min}$, primer-annealing at $44^{\circ} \mathrm{C}$ for $1 \mathrm{~min}$ and extension cycle at $72{ }^{\circ} \mathrm{C}$ for $1.5 \mathrm{~min}$, with a final extension at $72{ }^{\circ} \mathrm{C}$ for $10 \mathrm{~min}$. PCR-amplicons were visualized in $2 \%$ agarose gel electrophoresis and subsequently revealed with ethidium bromide staining. The amplified 16SrDNA gene product was sequenced using Sanger dideoxy method. Manual sequence edition, alignment, and contig assembly were performed using Vector NTI v10 software package. Sequencing results were analyzed for chimeras using DECIPHER v1.4.0 program [26]. The 16SrRNA gene sequences were compared with the GenBank/EMBL/ DDBJ databases by using the BLASTN [27] search program. After pair wise alignment using CLUSTAL_X program v1.8 [28], the phylogenetic tree of the wild-type isolate JB140 was constructed by neighbor-joining [29] method using MEGA X [30]. The evolutionary distance was computed using the Kimura 2-parameter method [31]. The stability of relationships was assessed by performing bootstrap analyses [32] of the neighbor-joining data based on 1000 re-samplings.

\section{Chemical characterization}

To characterize the proteinaceous nature of antimicrobial metabolites produced by the wild-type Streptomyces strain and its evolved mutants, methanolic extract of JB140 ${ }^{S a, S t, P v}$ (purified after III $^{\text {rd }}$ cycle) was investigated against proteolytic enzymes trypsin and proteinase K (Sigma). The methanolic extract of JB140 ${ }^{\text {Sa,St,Pv }}$ was mixed with trypsin and proteinase $\mathrm{K}$ at final concentrations of 0.5 and $10 \mathrm{mg} / \mathrm{ml}$, respectively. The reaction was incubated at $37^{\circ} \mathrm{C}$ for $24 \mathrm{~h}$. The temperature sensitivity was also examined by heating the methanolic extracts prepared from the 9-day grown cultivation broth of JB140 $0^{\mathrm{WT}}$ and $\mathrm{JB} 140^{P v}$, JB140 $0^{S t}$ JB140 ${ }^{S a}$, JB140 ${ }^{S a}, S t$, $\mathrm{JB} 140^{S a, P v}$, JB140 $0^{S t, P v}$, and JB140 ${ }^{S a, S t, P v}$ to $90{ }^{\circ} \mathrm{C}$ for $1 \mathrm{~h}$. Subsequently, the reactions were tested against the bacterial pathogens. The methanolic extracts prepared from the wild-type and evolved Streptomyces mutants were also analyzed by SDS-PAGE.

\section{RAPD profiling}

Random amplified polymorphic DNA (RAPD) analysis of the wild-type strain JB140 and its evolved mutants was performed by using random primers (Operon Technologies, USA); RAPD-1 5'AAGAGCCCGT3', RAPD-2 $5^{\prime}$ GTTTCCGCCC $3^{\prime}$ and RAPD-3 5'GAGGCCCTTC $3^{\prime}$. These three RAPD primers were used individually or in combination (all three) in separate PCR amplification cycles. The reaction started with an initial denaturation at $95{ }^{\circ} \mathrm{C}$ for $5 \mathrm{~min}$, followed by 40 cycles of DNA denaturation at $95{ }^{\circ} \mathrm{C}$ for $1 \mathrm{~min}$, primer-annealing at $32{ }^{\circ} \mathrm{C}$ for $1 \mathrm{~min}$, and extension cycle at $72^{\circ} \mathrm{C}$ for $1 \mathrm{~min}$, with a final extension at $72{ }^{\circ} \mathrm{C}$ for $10 \mathrm{~min}$. PCR-amplicons were visualized in $2 \%$ agarose gel electrophoresis after ethidium bromide staining. The detailed prototype of the present method has been also provided in supplementary data (Fig. S2).

\section{Results \\ Isolation and characterization of JB140}

Based on characteristic colonial morphology, notably the ability to form aerial hypha and substrate mycelia, earthy smell and chalky appearance of the mature colony, darker in the center and lighter farther, irregular, fuzzy edge, pigmented, strongly adhered and leathery texture, the isolate was putatively identified as actinobacteria. The Gram-positive actinobacterial isolate JB140 showed a typical mycelial structure in Gram's staining (Fig. 2A). The scanning electron micrograph of the isolate JB140 revealed that it has a long looped retinaculiaperti spore chain with a smooth surface (Fig. 2B). The isolate exhibited well-developed aerial and substrate mycelium on various ISP media (Fig. 3). 
16SrRNA gene sequence analysis and phylogeny

A comparison of the 16SrRNA gene sequence of the isolate JB140 was made against the available sequences in the GenBank database. It revealed homology of greater than $98 \%$ to the members of genera Streptomyces. It displayed 97.32 to $98.21 \%$ 16SrRNA gene sequence similarities to the closest type strain Streptomyces with 98.21\% identity to the nearest neighbor Streptomyces sp. BN71
(KF479179). The evolutionary relationship of the strain JB140 (MK855143) and the other 26 Streptomyces spp. has been provided in a phylogenetic tree in Fig. 4.

\section{Assessment of antimicrobial activity}

The isolate JB140 was analyzed for its antibacterial activity in primary and secondary screening against Proteus vulgaris, Salmonella Typhi, Staphylococcus aureus, and a

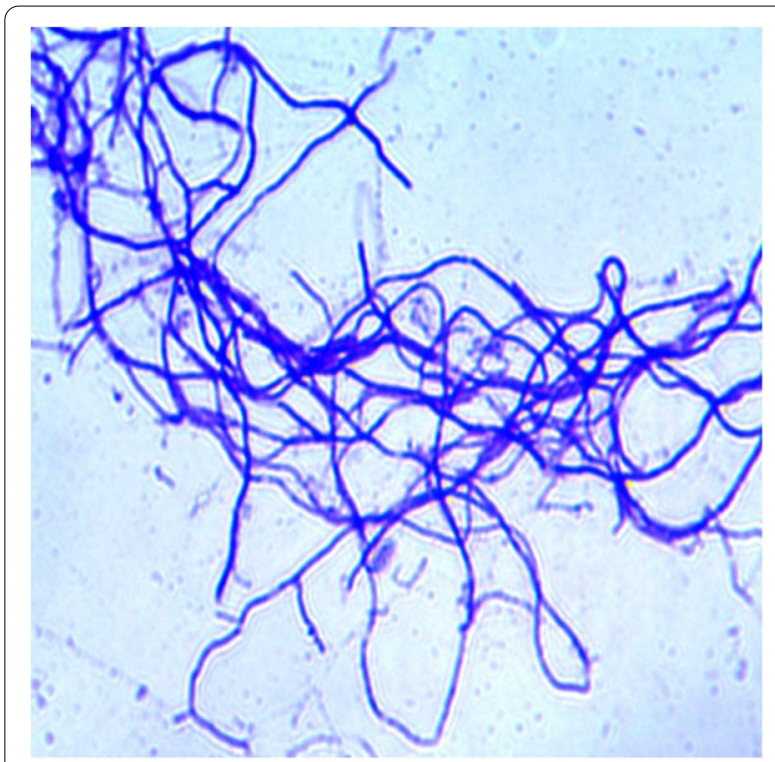

(A)

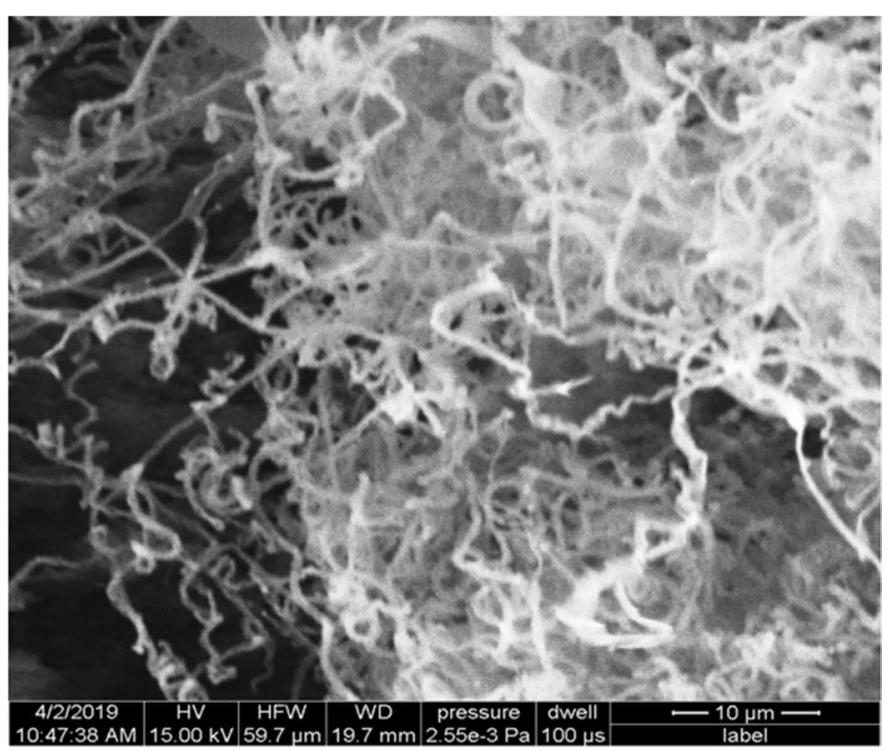

(B)

Fig. 2 Photomicrograph (× 1000) of mycelia $(\mathbf{A})$ and scanning electron micrograph of spores $(\mathbf{B})$ of Streptomyces isolate JB140

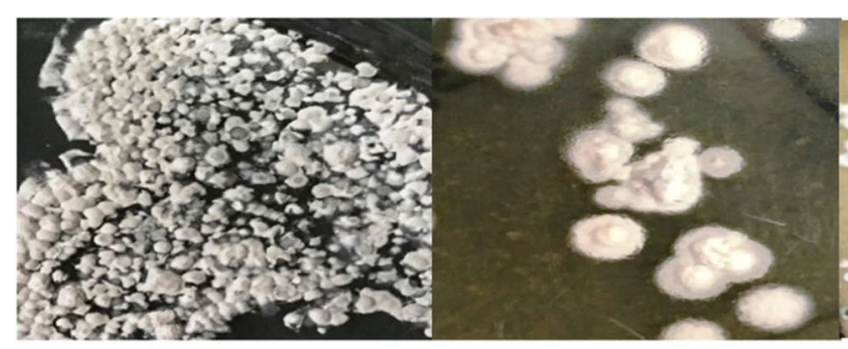

(A)

(B)

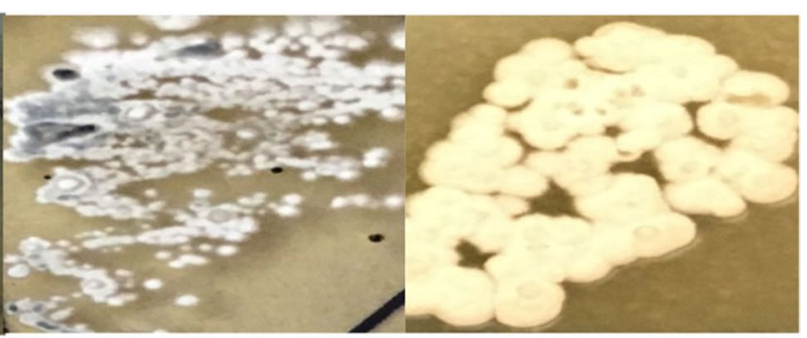

(C)

(D)

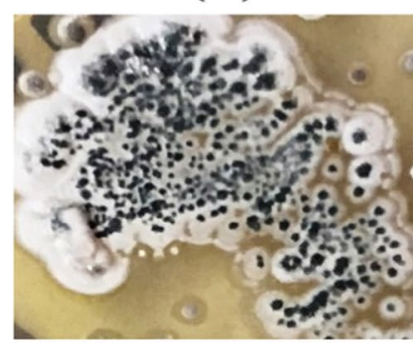

(E)

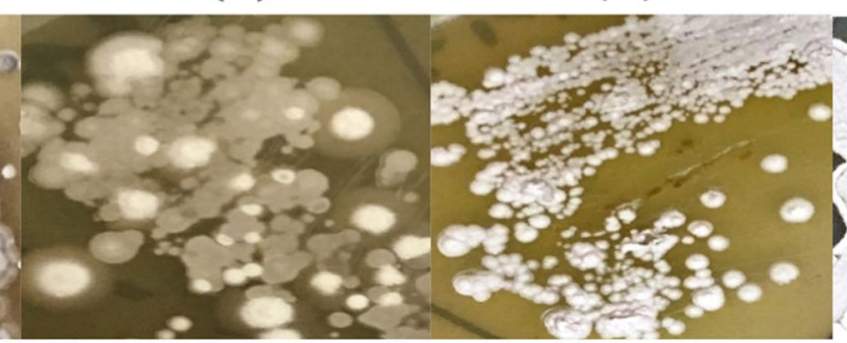

(F)

(G)

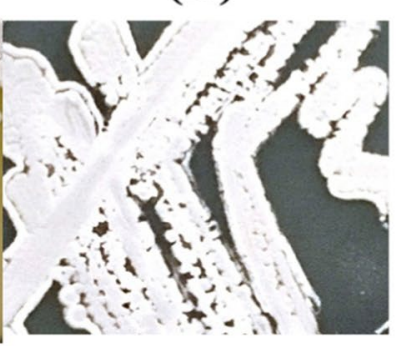

(H)

Fig. 3 Colonial appearance of the isolate JB140 on A modified actinomycetes specific (MAS) medium, B tryptone yeast extract agar (ISP1), C yeast extract maltose agar (ISP2), D oatmeal agar (ISP3), E inorganic salt starch agar (ISP4), F glycerol asparagine agar (ISP5), G peptone yeast extract iron agar (ISP6), $\mathbf{H}$ tyrosine agar (ISP7) 
clinical MDR UPEC. The antimicrobial activity of the isolate was estimated by measuring the diameter of the clear zone of growth inhibition (in mm scale). The methanolic extract of the isolate JB140 exhibited very little antimicrobial activity against the pathogenic bacteria tested as the inhibition zone of only $2-3 \mathrm{~mm}$ diameter was observed (Fig. 5).

\section{Adaptive evolution of Streptomyces JB140}

Using adaptive laboratory evolution protocol, Streptomyces strain $\mathrm{JB} 140^{\mathrm{WT}}$ competed against three different pathogens in the bi-, tri-, and quadri-culture experiments (Fig. 1). In 45-day-long competition experiments, after the third (III) cycle of adaptation-selection (after three serial passages of 10 days each) seven mutants were recovered and purified. After each cycle of adaptionselection, the antimicrobial activity of the wild-type and evolved mutants was assayed using the agar well diffusion method. An increased antimicrobial activity of the evolved mutants was noticed only after the third (III) cycle of adaptation-selection (Fig. 5). Whereas, after the first (I) and second (II) cycles of serial adaptationselection, very little or no antimicrobial activity was detected in the evolved mutants. These unique mutants, purified after the third (III) cycle of serial adaptationselection were designated as $\mathrm{JB}_{140}{ }^{P v}, \mathrm{JB}_{140}{ }^{S t}, \mathrm{JB} 140^{S a}$, and JB140 $0^{S a, S t}$, JB140 $0^{S a, P v}$, JB140 $0^{S t, P v}$, and JB140 $0^{S a, S t, P v}$. All seven mutants produced stable growth inhibitory activity against the tested pathogens. To ascertain that the stimulation of the production of antimicrobials in JB140 mutants is due to three serial adaptive-selection cycles wherein they were repeatedly exposed to the pathogens, JB140WT (a mono-culture experiment without a competing pathogen) was also inoculated using the same procedure. After 45 days (after III cycle in step 7), JB140 ${ }^{\text {WT }}$ was also assessed for its antimicrobial activity against the tested pathogens. The antimicrobial activity was observed to be similar as exhibited by its wild-type counterpart (Fig. 5). Contrary to this, the growth inhibitory effect of the evolved mutants against bacterial pathogens was observed to be from $9 \mathrm{~mm}$ to $14 \mathrm{~mm}$ in diameter. The highest antimicrobial activity of the evolved mutants was registered after 9-11 days duration and after that interval, it declined. Mutants JB140 $0^{S t, P v}$ and JB140 ${ }^{\text {Sa,St }}$ demonstrated the highest activity against $S$. Typhi (Fig. 5A) while mutants JB140 ${ }^{S a}, \mathrm{JB} 140^{S a, S t}$, and JB140 $0^{S a, S t, P v}$ were noticed to be highly active against $S$. aureus (Fig. 5B). The highest antimicrobial response was observed by

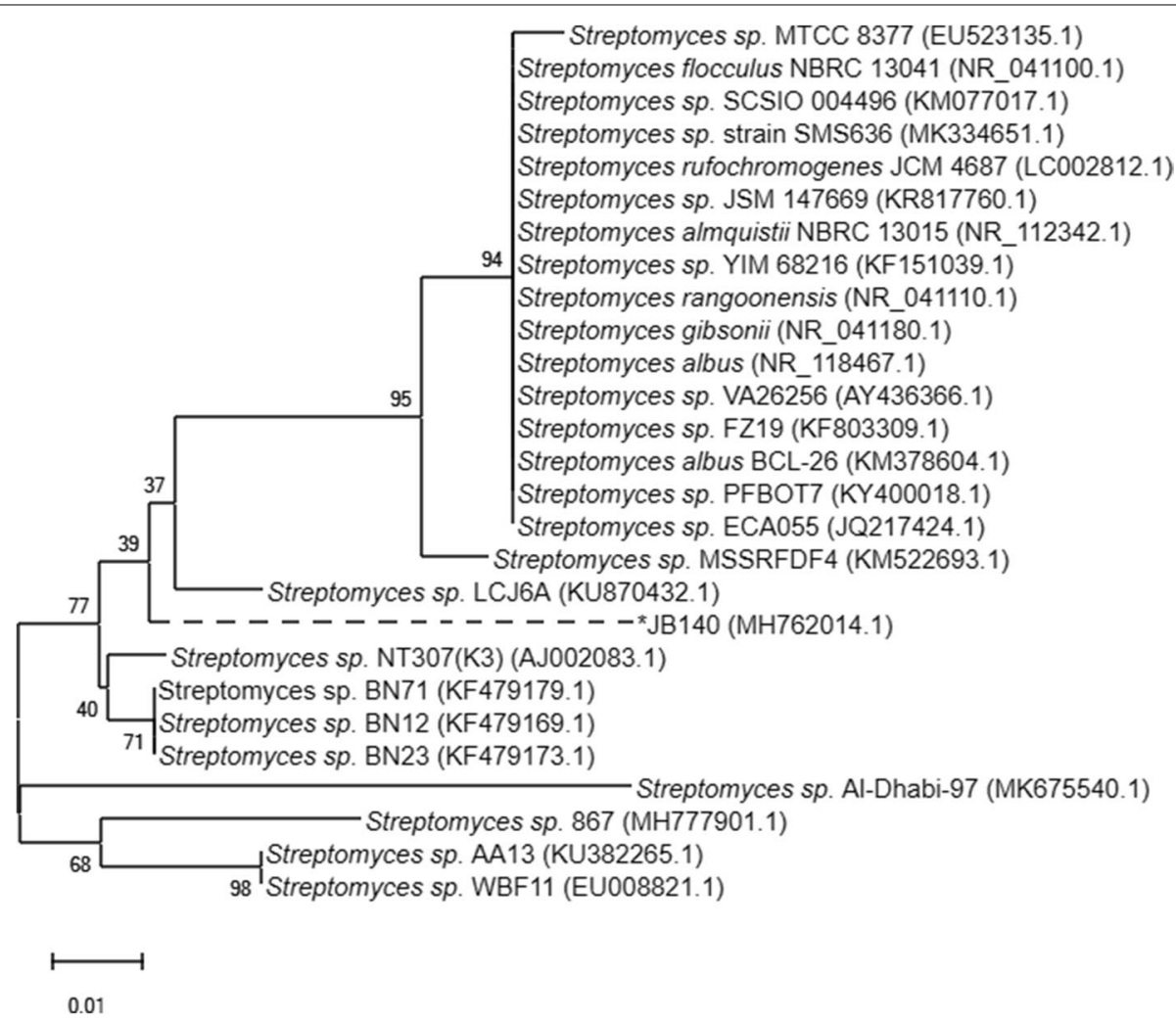

Fig. 4 Evolutionary relationship of JB140 was inferred using the neighbor-joining method. The tree is drawn to scale, with branch lengths in the same units as those of the evolutionary distances used to infer the phylogenetic tree. The evolutionary distances were computed using the Kimura 2-parameter method. The rate variation among sites was modeled with a gamma distribution (shape parameter $=2$ ). Evolutionary analysis was conducted in MEGAX 


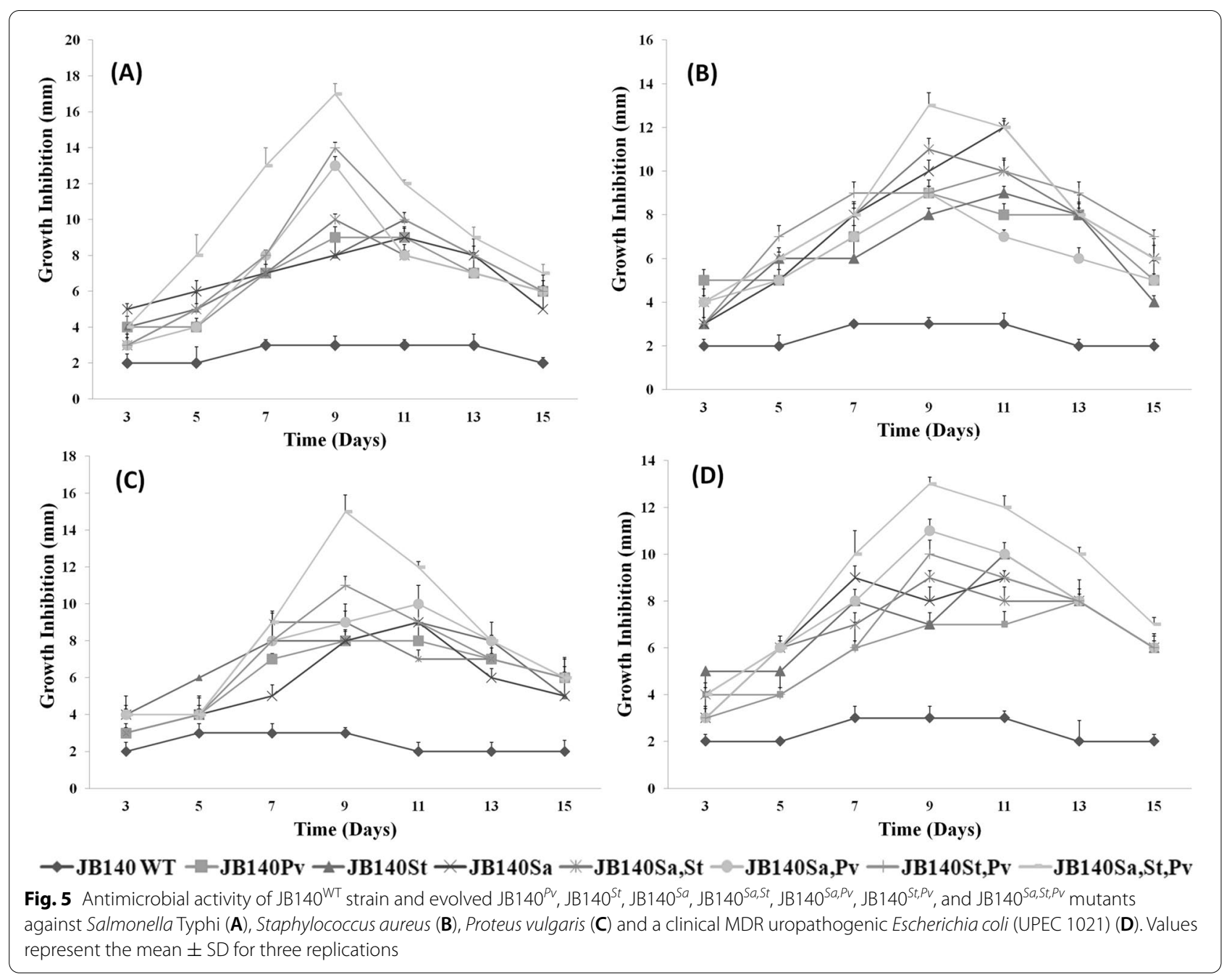

$\mathrm{JB} 140^{S t, P v}$ and $\mathrm{JB} 140^{S a, S t, P v}$ mutants against $P$. vulgaris, (Fig. 5C). Interestingly, all the evolved mutants were also found to exhibit antimicrobial activity against a clinical MDR uropathogenic Escherichia coli (UPEC 1021) and the highest activity was registered for the mutants $\mathrm{JB} 140^{S t, P v}$ and JB140 $0^{S a, S t, P v}$ (Fig. 5D). Furthermore, among seven different competition experiments, the highest antimicrobial activity was observed with the mutants that were evolved against the three pathogens (quadri-culture competition) (Fig. 5). The overall observations from the present study suggest that the growth inhibitory effect of the evolved mutants against the tested pathogens including clinical MDR uropathogenic E. coli appeared after three serial passages of adaptation-selection only and thus induced antimicrobial activity was not associated with $\mathrm{JB} 140^{\mathrm{WT}}$ parental strain. A similar growth inhibitory effect of the evolved mutants was also detected against nonpathogenic bacterial strains namely Escherichia coli (K-12 W3110) and Bacillus subtilis (NCIM 2920) (data not shown). Intriguingly, the whole process of laboratory-based adaptive evolution was reproducible and we could be able to replicate the results when the strategy was tested 3 months apart.

\section{Characterization of evolved mutants}

To confirm that the evolved mutants $\mathrm{JB} 140^{\mathrm{P \nu}}$, $\mathrm{JB}_{140}{ }^{S t}, \mathrm{JB} 140^{S a}, \mathrm{JB} 140^{S a, S t}, \mathrm{JB} 140^{S a, P v}, \mathrm{JB} 140^{S t, P v}$, and $J B 140^{S a, S t, P v}$ are indeed the true clone of Streptomyces $\mathrm{JB} 140^{\mathrm{WT}}$ and are not contaminants, the identity of these were confirmed using 16SrRNA gene sequence analyses. All seven mutants JB140 ${ }^{P v}$ (MK850143), $\mathrm{JB140}^{\text {St }}$ (MK852169), JB140 ${ }^{\text {Sa }}$ (MK852177), JB140 ${ }^{\text {Sa,St }}$ (MK852179), JB140 ${ }^{S a, P v} \quad$ (MK852175), JB140 ${ }^{S t, P v}$ (MK852170), and JB140 ${ }^{S a, S t, P v}$ (MK852176) were confirmed for their identity as Streptomyces, similar to their parental wild-type JB140 ${ }^{\text {WT }}$ (MK855143). Sequence comparison showed that all mutants were true clones of the JB140 ${ }^{\mathrm{WT}}$ strain (data not shown). The 
phenotypic characteristics of the evolved mutants were also observed to be the same as their parental JB140 ${ }^{\mathrm{WT}}$ strain (Fig. 6). The sensitivity of methanolic extract prepared from the evolved mutant JB140 ${ }^{S a, S t, P v}$ was unaffected to proteolytic enzymes trypsin and proteinase $\mathrm{K}$. The antimicrobial effect of $\mathrm{JB} 140^{S a, S t, P v}$ against all the tested bacterial pathogens was prominent (Fig. 7). The antimicrobial response of the $\mathrm{JB} 140^{\mathrm{WT}}$ and $\mathrm{JB} 140^{P v}$, $\mathrm{JB} 140^{S t}, \mathrm{JB} 140^{S a}, \mathrm{JB} 140^{S a, S t}, \mathrm{JB} 140^{S a, P v}, \mathrm{JB} 140^{S t, P v}$, and
JB140 ${ }^{S a, S t, P v}$ mutants were also observed to be retained at $90{ }^{\circ} \mathrm{C}$ (Fig. 8). Moreover, no protein or polypeptide band was observed when the wild-type JB140 and its mutants were analyzed by SDS-PAGE.

\section{RAPD profiling}

In support of adaptive evolution competition experiments and to get evidence of the evolution in actinobacterial $\mathrm{JB} 1400^{\mathrm{WT}}$, random amplified polymorphic

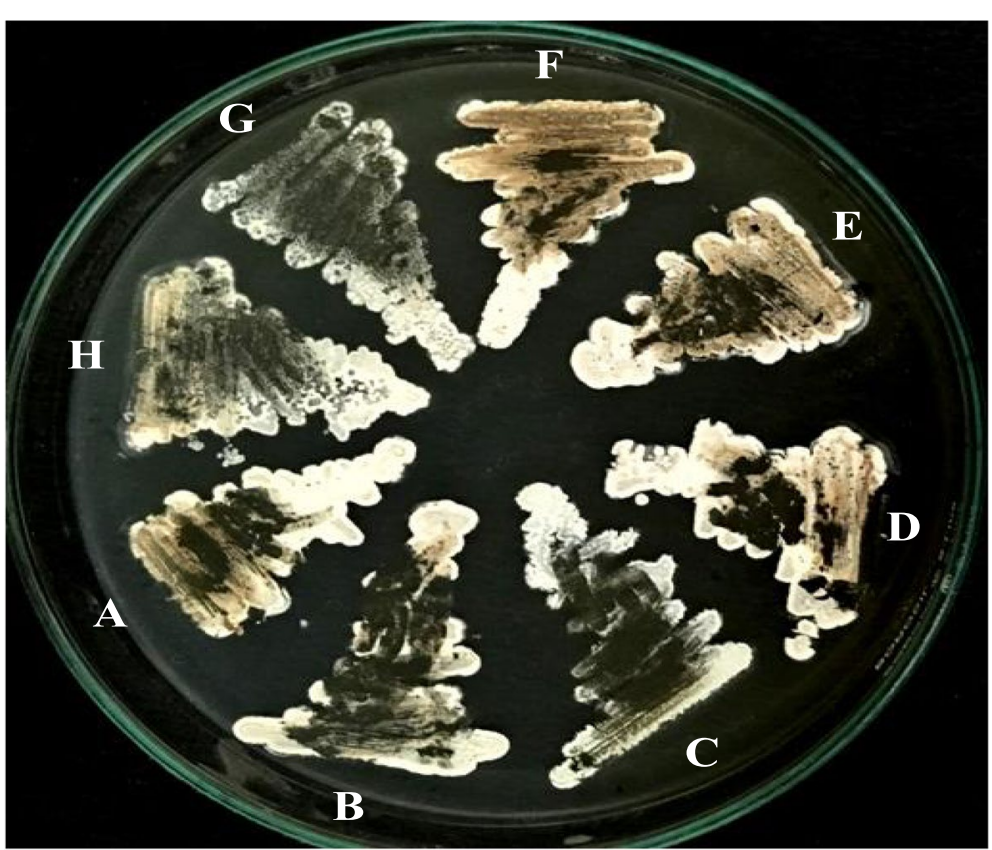

Fig. 6 Phenotypic appearance of Streptomyces strain JB140WT $(\mathbf{A})$ and its evolved mutants JB140 $0^{S t}(\mathbf{B}), J B 140^{S a}(\mathbf{C}), J B 140^{P v}\left(\right.$ D), JB140 $0^{S a, S t}(\mathbf{E})$, $\mathrm{JB} 140^{\mathrm{Sa}, P_{\mathrm{PV}}}(\mathbf{F}), \mathrm{JB} 140^{\mathrm{St}, \mathrm{PV}}(\mathbf{G})$, and JB140 $0^{\mathrm{Sa}, \mathrm{St}, \mathrm{PV}}(\mathbf{H})$ grown on ISP2 medium

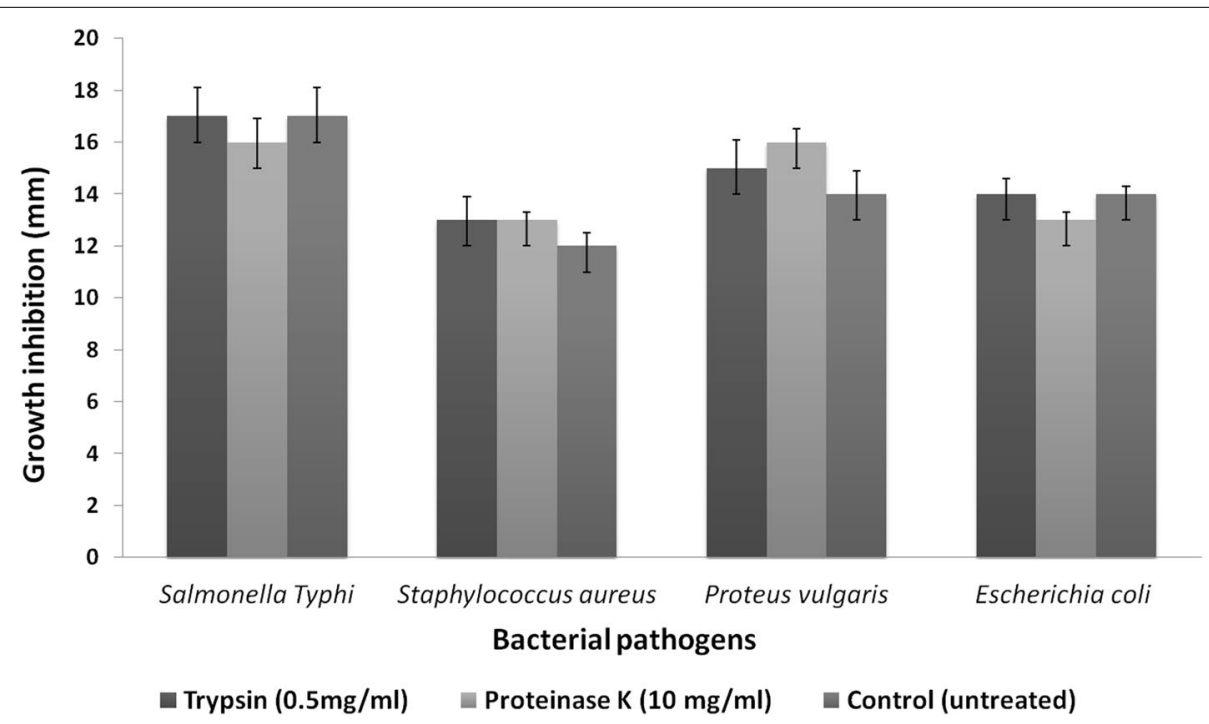

Fig. 7 Antimicrobial activity of JB140 Sa,St,Pv against Salmonella Typhi, Staphylococcus aureus, Proteus vulgaris, and a clinical MDR uropathogenic Escherichia coli isolate after treatment with $0.5 \mathrm{mg} / \mathrm{ml}$ trypsin and $10 \mathrm{mg} / \mathrm{ml}$ proteinase K. Values represent the mean \pm SD for three replications 


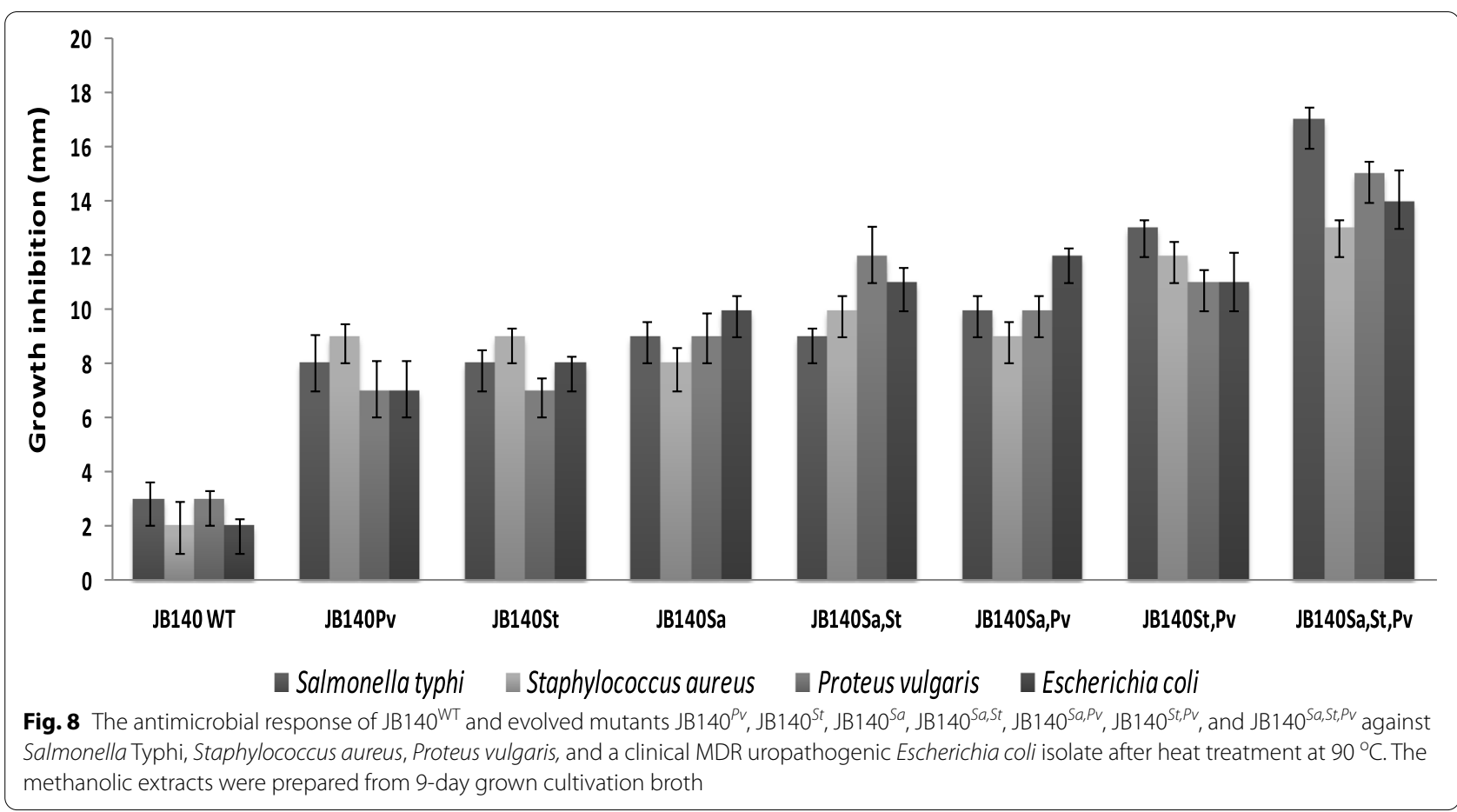

DNA analysis (RAPD) was performed. Genomic DNA of JB140 $0^{\mathrm{WT}}$ and $\mathrm{JB} 140^{P \nu}$, JB140 $0^{S t}$, JB140 ${ }^{S a}$, JB140 ${ }^{S a, S t}$, $\mathrm{JB} 140^{S a, P v}$, JB140 ${ }^{S t, P v}$, and JB140 ${ }^{S a, S t, P v}$ were amplified by using three RAPD primers $(1,2$, and 3$)$ and compared. The genomic DNA was amplified in separate amplification cycles using RAPD-1, RAPD-2, and RAPD-3 primers individually or in combination (all three). A large number of DNA bands were visualized in the RAPD profiles obtained from the wild-type strain and its mutants that represented significant genetic variations between them (Fig. 9). In a few instances, the RAPD-3 primer was not able to exhibit significant polymorphism between the evolved mutants (Fig. 9C). Similarly, we could not detect any polymorphic DNA in the case of JB140 ${ }^{\mathrm{Sa}, S t, P v}$ with RAPD-1,2,3 primers (Fig. 9D). Nevertheless, detectable differences were observed in the DNA profiles from the wild-type strain JB140 and its evolved mutants using RAPD-1 (Fig. 9A), RAPD-2 (Fig. 9B), and RAPD-1,2,3 primers (Fig. 9D).

\section{Discussion}

Many attempts have been made to develop laboratory methods to stimulate the production of novel secondary metabolites [33-38]. One of these methods includes adaptive laboratory evolution that has been successfully used to augment the production of antimicrobial molecules [39-43]. The adaptive laboratory evolution is a strategy in which a parent strain is serially passed against a certain selection pressure for few generations to promote adaptation to a new prevailing niche. The strategy has helped to increase our current understanding of natural laws of evolution that may further provide convincing solutions to the rising problems such as multidrug resistance [44-46]. Over a century ago, experiments involving adaptive laboratory evolution were originally performed [47-49]. However, in the present time, there has been an increase in the number of such experiments that involve microorganisms particularly yeast and bacteria to identify improved phenotypes and genotypes [40, 50-53]. A well-described example of this strategy is the adaptive laboratory evolution of antibiotic resistance in $E$. coli lineages under mild selection that displays a selective growth advantage independently of the acquired level of antibiotic resistance [53]. Moreover, the strategy can also assist to understand fundamental evolutionary principles that regulate detrimental adaptations [54]. Several other examples are also available in the literature that well describe this strategy such as the evolution of E. coli growing in glucose minimal medium to adapt in the media containing glycerol and lactate [55] and alteration in the productivity of industrially important chemicals $[56,57]$. Furthermore, the strategy has been also tested in different assays to observe ethanol tolerance [58-60], gene regulation in response to osmotic stress in Escherichia coli [61], and Streptomyces [62], activation of glycerol metabolism in Xanthomonas campestris [63] and enhanced extracellular electron transfer in Geobacter sulfurreducens [64]. 
It is important to note that the change in ecological niche causes the adaptive evolutionary process to occur in microbes, driven by genetic changes such as gain or loss, differential expression of existing genes [64-68]. We applied this strategy in the present work to study the importance of serial passages over time in the adaptive evolution of a Streptomyces wild-type strain with very little antimicrobial activity into the Streptomyces phenotypes (mutants) exhibiting broad-spectrum antimicrobial activity.

One of the main findings of the present work is that we were able to identify mutants that produced an increased amount of antimicrobials to inhibit the growth of bacterial pathogens effectively, including a clinical MDR uropathogenic Escherichia coli (UPEC 1021), as compared to their parental wild-type counterpart. Interestingly, when the challenge was posed by more than one pathogen in the assays, the stronger antimicrobial response was elicited by the producer strain. Among seven different competition experiments, the highest antibiotic response was registered with the mutants that were adaptively evolved against the three pathogens (quadri-culture competition). Thus, it could be stated that the evolved unique phenotypes arose only after three serial adaptation-selection cycles and not after initial, short-term exposure to the selection pressure. Other studies have been also performed in which augmented antibiotic production was observed wherein microorganisms were grown in a co-culture $[13-15,17,69,70]$. However, in the present study, the wild-type strain was not detected to exhibit antimicrobial potential until it was exposed to bacterial pathogens and serially passed for three successive cycles of 15 days each. And importantly, the requirement of repeated adaptation-selection cycles was crucial for the producer strain to exhibit stimulated production of antimicrobials against the target pathogens. The pathogens tested in the present study never faced serial passages. It may be speculated that during this period, competitive exclusion [71, 72] provoked the wild-type Streptomyces strain to synthesize chemical molecules to resist the challenge posed by the competing pathogen. When the wild-type Streptomyces strain was exposed to more than one pathogen, a higher antimicrobial response was evident. Although the type of chemical molecules (secondary metabolites) stimulated and the precise regulatory mechanism of transforming a wild-type Streptomyces strain exhibiting little antimicrobial effect into the phenotype with strong antimicrobial effect using this strategy is yet to be confirmed. Nevertheless, a simple procedure described in the present study certainly could assist in the discovery of yet undiscovered natural metabolites.
The antimicrobial response of the JB140 ${ }^{S a, S t, P v}$ mutant was insensitive to proteolytic enzymes trypsin and proteinase K. Moreover, the stability of the crude extracts at high temperature and the absence of protein bands in SDS-PAGE indicates that the antimicrobial metabolites produced by $\mathrm{JB} 140^{\mathrm{WT}}$ and $\mathrm{JB} 140^{P v}$, JB140 ${ }^{S t}, \mathrm{JB} 140^{S a}$, $\mathrm{JB} 140^{S a, S t}, \mathrm{JB} 140^{S a, P v}, \mathrm{JB} 140^{S t, P v}$, and JB140 $0^{S a, S t, P v}$ might not be proteinaceous. We could collect molecular evidence for the adaptive laboratory evolution by comparing RAPD profiles of the wild-type Streptomyces and its evolved mutants. To detect these genetic variations, three RAPD primers were tested individually and in combinations. In principle, there is no upper limit to the number of RAPD primers that can be used to detect the DNA polymorphism. It is also reasonable to believe that if " $n$ " primers are used in an RAPD assay, a total of " $x$ 2" bands should be generated provided no factors are limiting the RAPD reaction. However, as can be seen in Fig. 9D, wherein RAPD-1,2,3 primers were used in combination, the average number of polymorphic DNA does not increase expectedly and remained constant to some extent. This is consistent with the results of $\mathrm{Hu}$ et al. [73] and Säull [74], who compared single and multiple-primer RAPD reactions and observed that RAPD assays involving multiple primers, as compared to a single-primer, yield fewer bands on average. It was speculated that competition between multipleRAPD-primers in the reaction operates in such a way that after PCR amplification merely a subset of DNA polymorphic bands is detected [75, 76]. Nevertheless, in the present study, RAPD assays yielded significant polymorphism between the wild-type strain and its evolved mutants. However, the exact mutational events that occurred during this evolution are yet unknown. In this regard, future work will be important to reveal the underlying mechanism responsible for the laboratory-based adaptive evolution strategy. To apply and test this method on other systems, a detailed prototype has been also provided in the supplementary data of the manuscript (Fig. S1 and Fig. S2).

\section{Conclusion}

A wild-type Streptomyces strain exhibiting very little antimicrobial activity, when competed against bacterial pathogens using adaptive evolution protocol, was transformed into the unique mutant phenotype with increased antimicrobial profiles. These improved phenotypes were stable and acquired the ability to constitutively exhibit increased antimicrobial activity against various bacterial pathogens as compared to their parental wild-type counterpart. Moreover, the molecular evidence of the genetic variation collected using RAPD profiling revealed significant polymorphism in the evolved mutants. The constitutive overproduction of the 


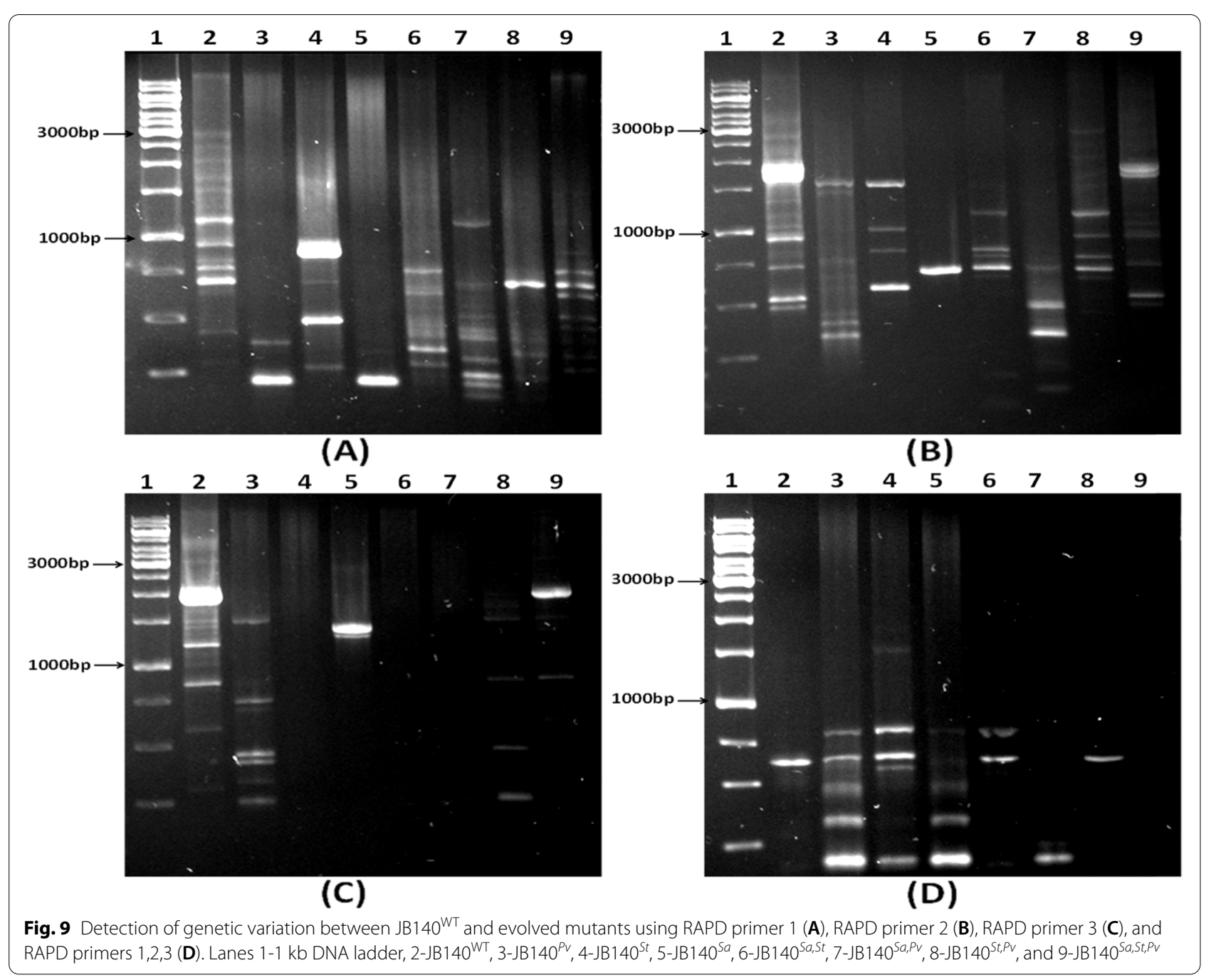

antimicrobials (non-proteinaceous) in the mutants was possibly due to the expression of genes that were silent or not expressed in the wild-type parent. Conclusively, the present study signifies that adaptive laboratory evolution is an efficient tool to select improved phenotypes that can overproduce target-dependent bioactive metabolites. The present study also provides a framework to design more improved selection methods to find out the possible solutions to the issues posed by MDR pathogens and provide much-needed novel and alternative antimicrobial therapy.

\section{Abbreviations}

WT: Wild type; MDR: Multidrug-resistant; RAPD: Random amplified polymorphic DNA; St: Salmonella Typhi; Sa: Staphylococcus aureus; Pv: Proteus vulgaris; MAS: Modified Actinomycete Selective; SEM: Scanning electron microscopy; ISP: International Streptomyces Project; UPEC: Uropathogenic Escherichia coli.

\section{Supplementary Information}

The online version contains supplementary material available at https://doi. org/10.1186/s43141-021-00283-3.

Additional file 1. Method details. Supplementary Fig. S1 A seven-step adaptive evolution protocol wherein a wild-type producer strain is competed against bacterial pathogens to stimulate antibiotic production. Supplementary Fig. S2 RAPD analysis to detect genetic variation between wild-type producer and evolved mutants using RAPD primers.

\section{Authors' contributions}

Conceptualization: $\mathrm{DH}$. Methodology: $\mathrm{DH}, \mathrm{JB}, \mathrm{SB}$, and JL. Formal analysis and investigation: $\mathrm{DH}, \mathrm{JB}, \mathrm{SB}$, and JL. Writing —original draft preparation: $\mathrm{DH}$. Writing - review and editing: $\mathrm{DH}$, and JL. Supervision: $\mathrm{DH}$. All authors have read and approved the manuscript.

\section{Availability of data and materials}

The authors declare that all data generated or analyzed in this study are included in the article. 


\section{Declarations}

\section{Ethics approval and consent to participate}

This article does not contain any studies related to humans or animals.

\section{Consent for publication}

Not applicable.

\section{Competing interests}

The authors declare that they have no competing interests.

Received: 16 June 2021 Accepted: 6 December 2021

Published online: 03 January 2022

\section{References}

1. Demain AL, Elander RP (1999) The beta-lactam antibiotics: past, present, and future. Antonie Van Leeuwenhoek 75:5-19

2. Appelbaum PC (2006) The emergence of vancomycin intermediate and vancomycin-resistant Staphylococcus aureus. Clin Microbiol Infect 12(1):16-23

3. Watve MG, Tickoo R, Jog MM, Bhole BD (2001) How many antibiotics are produced by the genus Streptomyces? Arch Microbiol 176:386-390

4. Newman DJ, Cragg GM (2007) Natural products as sources of new drugs over the last 25 years. J Nat Prod 70:461-477

5. Berdy J (2005) Bioactive microbial metabolites. A personal view. J Antibiot 58:1-26

6. Demain AL, Sanchez S (2009) Microbial drug discovery: 80 years of progress. J Antibiot (Tokyo) 62:5-16

7. Bentley SD, Chater KF, Cerdeno-Tarraga AM, Challis GL, Thomson NR, James KD, Harris DE, Quail MA, Kieser H, Harper D, Bateman A, Brown S, Chandra G, Chen CW, Collins M, Cronin A, Fraser A, Goble A, Hidalgo J, Hornsby T, Howarth S, Huang CH, Kieser T, Larke L, Murphy L, Oliver K, O'Neil S, Rabbinowitsch E, Rajandream MA, Rutherford K, Rutter S, Seeger K, Saunders D, Sharp S, Squares R, Squares S, Taylor K, Warren T, Wietzorrek A, Woodward J, Barrell BG, Parkhill J, Hopwood DA (2002) Complete genome sequence of the model actinomycete Streptomyces coelicolor A3(2). Nature 417:141-147

8. Ikeda H, Ishikawa J, Hanamoto A, Shinose M, Kikuchi H, Shiba T, Sakaki Y, Hattori M, Omura S (2003) Complete genome sequence and comparative analysis of the industrial microorganism Streptomyces avermitilis. Nat Biotechnol 21:526-531

9. Medema MH, Trefzer A, Kovalchuk A, van den Berg M, Muller U, Heijne W, Wu L, Alam MT, Ronning CM, Nierman WC, Bovenberg RA, Breitling R, Takano $E$ (2010) The sequence of a 1.8-mb bacterial linear plasmid reveals a rich evolutionary reservoir of secondary metabolic pathways. Genome Biol Evol 2:212-224

10. Ohnishi Y, Ishikawa J, Hara H, Suzuki H, Ikenoya M et al (2008) Genome sequence of the streptomycin-producing microorganism Streptomyces griseus IFO 13350. J Bacteriol 190:4050-4060

11. Song JY, Jeong H, Yu DS, Fischbach MA, Park HS, Kim JJ, Seo JS, Jensen SE, Oh TK, Lee KJ, Kim JF (2010) Draft genome sequence of Streptomyces clavuligerus NRRL 3585 , a producer of diverse secondary metabolites. J Bacteriol 192:6317-6318

12. Jiao J, Paterson J, Busche T, Rückert C, Kalinowski J, Harwani D, Gross H (2018) Draft genome sequence of Streptomyces sp. strain DH-12, a soilborne isolate from the Thar Desert with broad-spectrum antibacterial activity. Genome Announc 6:e00108-e00118

13. Slattery M, Rajbhandari I, Wesson K (2001) Competition-mediated antibiotic induction in the marine bacterium Streptomyces tenjimariensis. Microb Ecol 41:90-96

14. Oh DC, Kauffman CA, Jensen PR, Fenical W (2007) Induced production of emericellamides $\mathrm{A}$ and $\mathrm{B}$ from the marine-derived fungus Emericella $\mathrm{sp}$. in competing co-culture. J Nat Prod 70:515-520

15. Kurosawa K, Ghiviriga I, Sambandan TG, Lessard PA, Barbara JE et al (2008) Rhodostreptomycins antibiotics biosynthesized following horizontal gene transfer from Streptomyces padanus to Rhodococcus fascians. J Am Chem Soc 130:1126-1127
16. Bills G, Overy D, Genilloud O, Pelaez F (2009) Contributions of pharmaceutical antibiotic and secondary metabolite discovery to the understanding of microbial defense and antagonism. In: White JF Jr, Torres MS (eds) Defensive Mutualism in Microbial Symbiosis. CRC Press, Boca Raton, FL, pp 257-297

17. Harwani D, Begani J, Lakhani J (2018) Co-cultivation strategies to induce de-novo synthesis of novel chemical scaffolds from cryptic secondary metabolite gene clusters. In Gehlot P and Singh J eds. Fungi and their Role in Sustainable Development: Current Perspectives. Springer 617-631.

18. Srinivasan V, Nagaraja M, Parthasarathi A (2014) Highly deviated asymmetric division in very low proportion of mycobacterial mid-log phase cells. Open Microbiol J 8:40-50

19. Shirling ET, Gottlieb D (1966) Methods for characterization of Streptomyces species. Int I Syst Evol Microbiol 16(3):313-340

20. Jiménez-Esquilín AE, Roane TM (2005) Antifungal activities of actinomycete strains associated with high-altitude Sagebrush Rhizosphere. J Ind Microbiol Biotechnol 32:378-381

21. Elleuch L, Shaaban M, Smaoui S et al (2010) Bioactive secondary metabolites from a new terrestrial Streptomyces sp. TN262. Appl Biochem Biotechnol 162:579-593

22. Magaldi S, Mata-Essayag S, Hartung de Capriles C et al (2004) Well diffusion for antifungal susceptibility testing. Int J Infect Dis 8:39-45

23. Valgas C, De Souza SM, Smânia EFA et al (2007) Screening methods to determine antibacterial activity of natural products. Braz J Microbiol 38:369-380

24. Johnson JS, Spakowicz DJ, Hong BY, Petersen LM, Demkowicz P, Chen L, Leopold SR, Hanson BM, Agresta HO, Gerstein M, Sodergren E (2019) Evaluation of $16 \mathrm{~S}$ rRNA gene sequencing for species and strain-level microbiome analysis. Nat commun 10(1):1-1

25. Li JT, Yang J, Chen DC, Zhang XL, Tang ZS (2007) An optimized minipreparation method to obtain high-quality genomic DNA from mature leaves of sunflower. Genet Mol Res 6:1064-1071

26. Wright ES, Yilmaz LS, Noguera DR (2012) DECIPHER, a Search- Based Approach to Chimera identification for 16S rRNA sequences. Appl Environ Microbiol 78:717-725

27. Altschul SF, Madden TL, Schaffer AA, Zhang J, Zhang Z, Miller, W Lipman DJ (1997) Gapped BLAST and PSI-BLAST: a new generation of protein database search programs. Nucleic Acids Res 25:3389-3402

28. Thompson JD, Gibson TJ, Plewniak F, Jeanmougin F, Higgins DG (1997) The Clustal X windows interface: flexible strategies for multiple sequence alignment aided by quality analysis tools. Nucleic Acids Res $25: 4876-4882$

29. Saitou N, Nei M (1987) The neighbour-joining method: a new method for reconstructing phylogenetic trees. Mol Biol Evol 4:406-425

30. Kumar S, Stecher G, Li M, Knyaz C, Tamura K (2018) MEGA X: Molecular evolutionary genetics analysis across computing platforms. Mol Biol Evol 35:1547-1549

31. Kimura M (1980) A simple method for estimating evolutionary rate of base substitutions through comparative studies of nucleotide sequences. J Mol Evol 16:111-120

32. Felsenstein J (1985) Confidence limits on phylogeny: an appropriate use of the bootstrap. Evolution 39:783-791

33. Mutka SC, Carney JR, Liu Y, Kennedy J (2006) Heterologous production of epothilone C and D in Escherichia coli. Biochemistry 45:1321-1330

34. Gottelt M, Kol S, Gomez-Escribano JP, Bibb M, Takano E (2010) Deletion of a regulatory gene within the $c p k$ gene cluster reveals novel antibacterial activity in Streptomyces coelicolor A3(2). Microbiology 156:2343-2353

35. Scherlach K, Schuemann J, Dahse HM, Hertweck C (2010) Aspernidine A and $B$, prenylated isoindolinone alkaloids from the model fungus Aspergillus nidulans. J. Antibiot. (Tokyo). 63:375-377

36. Laureti L, Song L, Huang S, Corre C, Leblond P et al (2011) Identification of a bioactive 51 -membered macrolide complex by activation of a silent polyketide synthase in Streptomyces ambofaciens. Proc Natl Acad Sci USA 108:6258-6263

37. Baltz RH (2011) Strain improvement in actinomycetes in the postgenomic era. J Ind Microbiol Biotechnol 38:657-666

38. Garbeva P, Silby MW, Raaijmakers JM, Levy SB, Boer WD (2011) Transcriptional and antagonistic responses of Pseudomonas fluorescens PfO-1 to phylogenetically different bacterial competitors. ISME J 5(6):973-985 
39. Goers L, Freemont P, Polizzi KM (2014) Co-culture systems and technologies: taking synthetic biology to the next level. J R Soc Interface 11(96):20140065

40. Charusanti P, Fong NL, Nagarajan H, Pereira AR, Li HJ, Abate EA, Su Y, Gerwick WH, Palsson BO (2012) Exploiting adaptive laboratory evolution of Streptomyces clavuligerus for antibiotic discovery and overproduction PLoS One 7:1-12

41. Stergiopoulos J, Collemare J, Mehrabi R, De Wit PJ (2013) Phytotoxic secondary metabolites and peptides produced by plant pathogenic Dothideomycete fungi. FEMS Microbiol Rev 37:67-93

42. Blum P, Rudrappa D, Singh R, McCarthy S, Pavlik B (2016) Experimental microbial evolution of extremophiles. In Rampelotto PH ed. Biotechnology of extremophiles: grand challenges in biology and biotechnology, Vol. 1, Cham; Heidelberg; New York, NY; London; Dordrecht: Springer International Publishing, 619-636

43. Chunxiao Xu, Tao Sun, Shubin Li, Lei Chen, Weiwen Zhang (2018) Adaptive laboratory evolution of cadmium tolerance in Synechocystis sp. PCC 6803. Biotechnol Biofuels 11:205

44. Cohen SP, McMurry LM, Hooper DC, Wolfson JS, Levy SB (1989) Crossresistance to fluoroquinolones in multiple-antibioticresistant (Mar) Escherichia coli selected by tetracycline or chloramphenicol: decreased drug accumulation associated with membrane changes in addition to OmpF reduction. Antimicrob Agents Chemother 33:1318-1325

45. Donald PR, van Helden PD (2009) The global burden of Tuberculosis combating drug resistance in difficult times. N Engl J Med 360:2393-2395

46. Wellenreuther M, Mérot C, Berdan E, Bernatchez L (2019) Going beyond SNPs: The role of structural genomic variants in adaptive evolution and species diversification. Mol ecol 28(6):1203-1209

47. Dallinger WH (1887) The president's address. J R Microsc Soc 10:185-199

48. Haas JW Jr (2000) The Reverend Dr. William Henry Dallinger, frs. (18391909). Notes Rec R Soc Lond 54(1):53-65

49. Bennett AF, Hughes BS (2009) Microbial experimental evolution. Am J Physiol Regul Integr Comp Physiol 297:R17-R25

50. Fong SS, Joyce AR, Palsson BO (2005) Parallel adaptive evolution cultures of Escherichia coli lead to convergent growth phenotypes with different gene expression states. Genome Res 15:1365-1372

51. Shui ZX, Qin H, Wu B, Ruan ZY, Wang LS, Tan FR, Wang JL, Tang XY, Dai LC, Hu GQ, He MX (2015) Adaptive laboratory evolution of ethanologenic Zymomonas mobilis strain tolerant to furfural and acetic acid inhibitors. Appl Microbiol Biotechnol 99:5739-5748

52. LaCroix RA, Palsson BO, Feist AM (2017) A Model for designing adaptive laboratory evolution experiments. Appl Environ Microbiol 83:e00410-e00417

53. Jahn LJ, Munck C, Ellabaan MM, Sommer MO (2017) Adaptive laboratory evolution of antibiotic resistance using different selection regimes lead to similar phenotypes and genotypes. Front Microbiol 8:816

54. Riganti C, Mini E, Nobili S (2015) Editorial: multidrug resistance in cancer: pharmacological strategies from basic research to clinical issues. Front Oncol 5:105

55. Conrad TM, Joyce AR, Applebee MK, Barrett CL, Xie B, Gao Y, Palsson B (2009) Whole-genome resequencing of Escherichia coli K-12 MG1655 undergoing short-term laboratory evolution in lactate minimal media reveals flexible selection of adaptive mutations. Genome Biol 10(10):R118

56. Trinh CT, Srienc F (2009) Metabolic engineering of Escherichia coli for efficient conversion of glycerol to ethanol. Appl Environ Microbiol 75:6696-6705

57. Hu H, Wood TK (2010) An evolved Escherichia coli strain for producing hydrogen and ethanol from glycerol. Biochem. Biophys. Res Commun 391:1033-1038

58. Horinouchi T, Tamaoka K, Furusawa C, Ono N, Suzuki S, Hirasawa T, Yomo T, Shimizu H (2010) Transcriptome analysis of parallel-evolved Escherichia coli strains under ethanol stress. BMC genomics 11:579

59. Stanley D, Fraser S, Chambers PJ, Rogers P, Stanley GA (2010) Generation and characterisation of stable ethanol-tolerant mutants of Saccharomyces cerevisiae. J Ind Microbiol Biotechnol 37:139-149

60. Wang Y, Manow R, Finan C, Wang J, Garza E, Zhou S (2011) Adaptive evolution of nontransgenic Escherichia coli KC01 for improved ethanol tolerance and homoethanol fermentation from xylose. J Ind Microbiol Biotechnol 38:1371-1377
61. Stoebel DM, Hokamp K, Last MS, Dorman CJ (2009) Compensatory evolution of gene regulation in response to stress by Escherichia coli lacking RpoS. PLoS genetics 5:e1000671

62. Zhao F, Qin YH, Zheng X, Zhao HW, Chai DY, Li W, Pu MX, Zuo XS, Qian W, Ni P, Zhang Y (2016) Biogeography and adaptive evolution of Streptomyces strains from saline environments. Scientific reports 6(1):1-9

63. Wang Z, Wu J, Zhu L, Zhan X (2016) Activation of glycerol metabolism in Xanthomonas campestris by adaptive evolution to produce a high-transparency and low-viscosity xanthan gum from glycerol. Bioresour Technol 211:390-397

64. Tremblay PL, Summers ZM, Glaven RH, Nevin KP, Zengler K, Barrett CL, Qiu Y, Palsson BO, Lovley DR (2011) A c-type cytochrome and a transcriptional regulator responsible for enhanced extracellular electron transfer in Geobacter sulfurreducens revealed by adaptive evolution. Environ Microbiol 13:13-23

65. Shapiro BJ, Leducq JB, Mallet J (2016) What is speciation? PLoS Genet 12:e1005860

66. Vos M (2011) A species concept for bacteria based on adaptive divergence. Trends Microbiol 19:1-7

67. Toft C, Andersson SG (2010) Evolutionary microbial genomics: insights into bacterial host adaptation. Nat Rev Genet 11:465-475

68. Li Y, Pinto-Tomás AA, Rong X, Cheng K, Liu M, Huang Y (2019) Population genomics insights into adaptive evolution and ecological differentiation in streptomycetes. Appl Environ Microbiol 85(7):e02555-e02518

69. Perry MJ, Makins JF, Adlard MW, Holt G (1984) Aspergillic acids produced by mixed cultures of Aspergillus flavus and Aspergillus nidulans. J Gen Microbiol 130:319-323

70. Sonnenbichler J, Lamm V, Gieren A, Holdenrieder O, Lotter H (1983) A cyclopentabenzopyranone produced by the fungus Heterobasidion annosum in dual cultures. Phytochemistry 22:1489-1491

71. Gause GF (1932) Experimental studies on the struggle for existence. J Exp Biol 9:389-402

72. Hardin G (1960) The competitive exclusion principle. Science 131:1292-1297

73. Hu J, van Eysden J, Quiros CF (1995) Generation of DNA-based markers in specific genome regions by two-primer RAPD reactions. PCR Methods Appl 4:346-351

74. Säull T, Lind-Halldén C, Halldén C (2000) Primer mixtures in RAPD analysis. Hereditas 132(3):203-208

75. Williams JGK, Hanafey MK, Rafalski JA, Tingey SV (1993) Genetic analysis using randomly amplified polymorphic DNA markers. Meth Enzymology 218:704-740

76. Hallden C, Hansen M, Nilsson N-0, Hjerdin A and Sall T (1996). Competition as a source of errors in RAPD analysis. Theor Appl Gen 93:1 185-1192

\section{Publisher's Note}

Springer Nature remains neutral with regard to jurisdictional claims in published maps and institutional affiliations.

\section{Submit your manuscript to a SpringerOpen ${ }^{\circ}$ journal and benefit from:}

- Convenient online submission

- Rigorous peer review

- Open access: articles freely available online

- High visibility within the field

- Retaining the copyright to your article

Submit your next manuscript at springeropen.com 